\title{
The Effect of Different Counselors on Treatment Outcome of Tinnitus Retraining Therapy
}

\author{
Woo Jin Kim, Ji Sun Kong, So Young Park, Ki Hwan Jung, \\ Rae Hyung Kim, Sang Won Yeo, and Shi Nae Park \\ Department of Otolaryngology-HNS, The Catholic University of Korea College of Medicine, Seoul, Korea
}

\author{
상담자 요소가 이명재훈련치료의 효과에 미치는 영향 \\ 김우진 · 공지선 · 박소영 · 정기환 · 김래형 · 여상원 · 박시내 \\ 가톨릭대학교 의과대학 이비인후과학교실

Received September 6, 2016
Revised January 4, 2017
Accepted January 5, 2017
Address for correspondence
Shi Nae Park, MD, PhD
Department of Otolaryngology-
HNS, The Catholic University of
Korea College of Medicine,
222 Banpo-daero, Seocho-gu,
Seoul 06591, Korea
Tel+82-2-2258-6215
Fax+82-2-2258-1354
E-mail snparkmd@catholic.ac.kr
Background and Objectives Tinnitus retraining therapy (TRT) is one of the most effective treatment modalities of tinnitus based on the neurophysiological model proposed by Jastreboff and Hazell. This study was performed to evaluate the effect of counselor factor on treatment outcomes of TRT.

Subjects and Method The total of 78 patients who had TRT from three different counselors in a tinnitus clinic of tertiary referral center from Jan 2015 to Dec 2015 were included in this study. Their medical records were retrospectively reviewed to evaluate the therapeutic response to TRT.

Results Among 78 patients who were followed-up for more than 6 months, 47, 20, and 11 patients were treated by counselors A, B, C (all ENT specialists), respectively. Counselor A had 15-year-experience of TRT counseling, whereas counselor B and C were well trained but beginners of TRT counseling. Initial clinical characteristics including Tinnitus Handicap Inventory (THI) and tinnitus Visual Analogue Scale (VAS) scores of the patients among three groups were not significantly different. Treatment responses evaluated via THI and most of the tinnitus VAS scores after at least 6 months after TRT were significantly improved in all three groups $(p<0.05)$ with no significant difference between the senior (A) and junior (B, C) group. Conclusion TRT seems to be an effective treatment modality of tinnitus even in this short term follow-up study. Treatment outcomes of TRT may not depend on the counselors once they are well trained and follow the same protocol.

Korean J Otorhinolaryngol-Head Neck Surg 2017;60(5):209-14

Key Words Counselor - Tinnitus - Tinnitus retraining therapy.

\section{서 론}

이명재훈련치료(tinnitus retraining therapy, TRT)는 Jastreboff와 Hazell에 의해 제안된 신경생리학적 모델에 기초 한 이명의 효과적인 치료 중의 하나로 알려져 있다. 이명의 신

This is an Open Access article distributed under the terms of the Creative Commons Attribution Non-Commercial License (http://creativecommons.org/licenses/by-nc/4.0) which permits unrestricted non-commercial use, distribution, and reproduction in any medium, provided the original work is properly cited.
경생리학적 모델이란 이명의 발생과 탐지, 인식의 과정에 청 각계 이외에 감정계 및 신체 반응계가 관여하여 이명 환자들 이 느끼는 심한 괴로움을 유발시키고 악화시킨다는 것이다. 이를 바탕으로 한 이명재훈련치료는 이명을 무의미하고 자연 스러운 소리로 인식하게끔 신경 회로 내에서 이명관련 신경신 호를 재편성하고, 익숙하면서 중요한 여러 일상의 소리로부터 무의미하고 중요하지 않은 이명 신호를 구별하여 듣지 않도록 재조정하는 과정으로 크게 지시적 상담(directive counseling) 
과 소리치료(sound therapy)로 구성된다. ${ }^{1-3)}$ 이명재훈련치료 의 삶의 질 개선 효과는 이미 여러 연구에서 밝혀진 바가 있으 며, 이를 바탕으로 전 세계 여러 이명센터에서 이명재훈련치 료를 시행하고 있다. ${ }^{4-6)}$ 이제 이명재훈련치료는 그 치료 효과 뿐만 아니라 여러 가지 방법론적인 측면에서의 연구가 필요하 고 또 진행 중인 상황이다.

이명재훈련치료의 방법론적인 측면에서 시행된 국내 연구 를 살펴보면, 소리치료의 경우 광대역 잡음이 가장 효과적인 것으로 나타났으며, 지시적 상담 치료의 경우 상담자가 상대 하는 환자 수에 따른 치료 효과는 큰 차이가 없는 것으로 나 타났다. ${ }^{78)}$

본 연구는 동일한 프로토콜에 따라 지시적 상담을 진행할 경우 상담자에 따른 이명재훈련치료의 결과가 치료 효과면에 서 차이를 보이는지를 분석하여 상담자 요소가 이명재훈련치 료에 미치는 영향을 관찰하고자 시행하였다.

\section{대상 및 방법}

\section{대 상}

2015년 1월에서 12월까지 병원 이명센터에 이명을 주소로 내원하여 이명재훈련치료를 받은 환자 중 6개월 추적관찰이 가능했던 환자 78명을 대상으로 본 대학 병원의 임상연구 심 의위원회의 승인을 받은 후(KC16RASI0708) 의무 기록 분석 을 통한 후향적 연구로 진행되었다.

\section{방 법}

\section{본 이명 클리닉에서의 진단 및 치료 과정}

본 이명 클리닉에 내원한 모든 이명 환자는 초진 시 이명 설 문지와 함께 문진을 통해 기본적인 병력을 파악하도록 하였 다. 순음청력도, 어음청력도, 고실도, 청성뇌간유발반응검사, 이명도 검사를 포함한 다양한 청각학적 검사 및 영상검사를 시행하여 다른 원인에 의한 이명 환자를 제외하고 감각신경 성 이명 환자를 대상으로 연구를 진행하였다. 이명재훈련치료 6 개월 후 이명 설문지를 다시 시행하여 치료 효과를 평가하였 다. 상담자 $\mathrm{A}$ 에게 내원한 초진 환자 수가 상담자 $\mathrm{B}$ 나 $\mathrm{C}$ 에 비 해 월등히 많은 본 이명 클리닉의 진료 구조로 인해, 상담자 $\mathrm{A}$ 를 찾았던 환자 중 일부가 상담자 $\mathrm{B}, \mathrm{C}$ 에게 지시적 상담을 받았고, 그 외 나머지 환자들은 상담자 $\mathrm{A}$ 에게 지시적 상담을 받았다.

\section{설문 조사}

환자들은 초진 시 이명 설문지를 시행하여 이명재훈련치료
전 설문 자료로 사용하였으며, 이명재훈련치료 6개월 후 설문 지를 다시 시행하여 비교 분석을 시행하였다. 이명 설문지에 는 이명의 기간, 양상, 부위 등의 기본적인 이명에 대한 정보와 함께 이명의 크기(loudness, LD), 이명을 느끼는 시간(awareness, AW), 이명으로 인한 괴로움(annoyance, AN), 이명이 생활에 미치는 불편함의 정도(effect on life, $\mathrm{EF}$ )를 시각화척 도(Visual Analog Scale) 1 10점까지 평가하도록 되어 있으며, 이명장애척도(Tinnitus Handicap Inventory, THI)도 포함되 어 있다.

\section{이명 상담자의 분류}

이명 환자는 총 세 명의 상담자 A, B, C 중 한 명에게 배정 되어 이명재훈련치료를 받았다. 상담자 $\mathrm{A}$ 는 15 년 이상 이명재 훈련치료의 경험이 있는 이비인후과 전문의로 "Senior"로 분 류하였다. A의 나이는 49세이고, 1999년에 이비인후과 전문 의 자격증을 취득 후 현재까지 이과 전문의로 활동 중이다.

상담자 $\mathrm{B}$ 와 $\mathrm{C}$ 는 이명에 대한 지식이 풍부하되 상담 치료 의 경험이 많지 않은 이비인후과 전문의로, $\mathrm{B}$ 와 $\mathrm{C}$ 를 묶어서 “Junior”로 분류하였다. B와 C는 모두 2015년에 이비인후과 전문의 자격증 취득 후 이명재훈련치료를 시작하였으며, 현 재까지 이과를 전공하고 있다. $\mathrm{B}$ 의 나이는 32 세, $\mathrm{C}$ 의 나이는 36 세이다. B와 C는 다른 상담자였지만 동일한 경력의 이비인 후과 전문의로 이명재훈련치료에 대한 교육을 철저히 받고 그 개념을 학습한 자들로 이비인후과적 지식과 이명 관련 지 식이나 경험의 차이는 없는 것으로 가정하였다. 상담자 $\mathrm{A}, \mathrm{B}$, $\mathrm{C}$ 는 모두 같은 프로토콜을 따라서 이명재훈련치료를 시행하 였다.

\section{이명재훈련치료의 프로토콜}

모든 이명 환자에 대해서 지시적 상담을 다음과 같은 순서 및 내용으로 시행하였다.9) 먼저 환자 개개인의 청각학적 및 내과적 검사결과를 충분히 설명하여 자신의 의학적 상태에 대해 이해하도록 하였다. 그리고 이명 발생기전과 관련하여 자세한 설명을 통해 이명에 대해 올바로 이해함으로써 이명 에 대한 부정적인 인식을 불식시키도록 하였다. 그 다음으로 소리치료 과정에 대한 설명을 포함한 이명재훈련치료 과정에 대해서 설명하여 환자가 치료 과정에 대해 이해하고 적극적 으로 참여하도록 유도하였다. 마지막으로 질문과 답변을 통 하여 환자 개개인의 이명에 대한 의문점을 해소하도록 하였 다. 특히 초기의 지시적 상담은 이명의 발생기전에 대한 지식 과 이해를 통해 긍정적인 생각을 갖게 함으로써 반응의 습관 화(habituation of reaction)를 유도할 수 있도록 충분한 설 명을 하였다. 또한 환자를 이명 카테고리(category)에 따라 
분류하고, 카테고리 0,1 환자는 환경음을 충분히 활용한 소 리치료를 권하였고, 이명 감소 효과가 충분치 않을 때 소리 발생기 처방 및 착용을 권하였으며, 청각과민증을 지닌 카테 고리 3,4 환자에 대해서는 치료 기간을 줄이고 빠른 습관화 를 유도하기 위해 소리 발생기를 가능한 조기에 처방하여 하 루 8시간 이상 착용하게 하였다. 난청을 동반한 카테고리 2 환자에게는 보청기 처방과 착용을 적극 권하였다.

\section{통계적 분석}

연구 디자인과 통계 분석은 통계학교실의 지원을 받아 시행 하였고, SAS version 9.4(SAS Institute Inc., Cary, NC, USA) 통계 프로그램을 이용하여 진행되었다. 이명 환자들의 임상 적 특성의 분석에는 independent t-test가 사용되었다. 각 그 룹별 비교 시에는 먼저 정규성 검증을 시행하여 정규성을 보 이는 경우에는 independent t-test를(상담자 A 환자군), 그렇 지 않은 경우에는 Wilcoxon rank sum test를 시행하였다(상 담자 B, C 환자군). 연속 변수에 대해서는 Wilcoxon rank sum test를, 범주형 변수에 대해서는 chi square test를 사용하였 다. 상담자와 이명의 호전과의 관계는 연속 변수인지 범주형 변수인지에 따라 independent t-test, paired t-test, 그리고 chi

Table 1. Baseline clinical characteristics of tinnitus patients between senior and junior counselor groups

\begin{tabular}{lccc}
\hline & Senior $(\mathrm{n}=47)$ & Junior $(\mathrm{n}=31)$ & $\mathrm{p}$ value \\
\hline Age & $52.38 \pm 14.24$ & $51.52 \pm 13.91$ & 0.791 \\
Sex (male) & $24(51.1)$ & $18(58.1)$ & 0.544 \\
Duration (month) & $6(2-36)$ & $4(2-12)$ & 0.666 \\
Hearing loss & $11(23.4)$ & $5(16.1)$ & 0.436 \\
Dizziness & $4(8.5)$ & $3(9.7)$ & 1.000 \\
Comorbidity & & & \\
$\quad$ HBP & $7(14.9)$ & $4(12.9)$ & 1.000 \\
DM & $3(6.4)$ & $1(3.2)$ & 1.000 \\
Site & & & 0.866 \\
Left & $12(25.5)$ & $10(32.3)$ & \\
Right & $12(25.5)$ & $8(25.8)$ & \\
Bilt & $22(46.8)$ & $12(38.7)$ & \\
Head & $1(2.1)$ & $1(3.2)$ & \\
Pitch & & & 0.236 \\
High & $26(55.3)$ & $23(74.2)$ & \\
Mid & $14(29.8)$ & $5(16.1)$ & \\
Low & $7(14.9)$ & $3(9.7)$ & \\
Tinnitus status & & & 0.784 \\
Low & $10(21.3)$ & $5(16.1)$ & \\
Moderate & $19(40.4)$ & $12(38.7)$ & \\
Severe & $18(38.3)$ & $14(45.2)$ & \\
\hline
\end{tabular}

Senior: patients who received directive counseling by senior counselor, Junior: patients who received directive counseling by junior counselor, HBP: hypertension, DM: diabetes mellitus square test를 이용하여 분석하였다. 치료 효과를 판정하기 위해서 치료 전후 이명 설문지상 각 항목 수치의 델타값 $(\Delta$ value)을 계산하여 사용하였다. 결측치에 대해서는 last observation carried forward 방법을 이용하여 수치를 대체하여 분석하였다. 유의수준이 0.05 이하일 때 통계학적으로 유의하 다고 판단하였다.

\section{결 과}

\section{치료 전 각 환자군의 임상적 특성}

본 연구 결과 78명의 환자가 상담자 $\mathrm{A}, \mathrm{B}$, 또는 C에게 이 명재훈련치료를 받았고 6 개월 이상 추적관찰 되었으며, 각 군에 해당하는 환자는 각각 47명, 20명, 11명이었다. Senior 와 junior 상담자의 환자군 사이에 치료 전 나이, 성별, 순음 청력도상 난청의 유무44분법으로 계산 후 $40 \mathrm{~dB}$ 이상을 난 청이 있다고 간주함), 이명의 기간, 동반 질환, 이명의 위치, 양 상, 스트레스 수치 등의 임상적 특성은 유의한 차이가 없었으 며(Table 1), junior군 내에서 상담자 B와 C의 환자군 사이에 도 치료 전 임상적 특성의 차이는 없었다(Table 2). 이명재훈 련치료 전 이명 설문지상 각 항목 수치들도 senior 환자군과 junior 환자군 사이, junior 환자군 내에서 상담자 $\mathrm{B}$ 와 $\mathrm{C}$ 의 환

Table 2. Baseline clinical characteristics of tinnitus patients between two junior counselor groups

\begin{tabular}{lccc}
\hline & Junior B $(\mathrm{n}=20)$ & Junior $\mathrm{C}(\mathrm{n}=11)$ & $\mathrm{p}$ value \\
\hline Age & $52.85 \pm 13.51$ & $49.09 \pm 14.95$ & 0.481 \\
Sex (male) & $13(65.0)$ & $5(45.5)$ & 0.449 \\
Duration (month) & $6.0(2.5-12.0)$ & $4(2-36)$ & 0.917 \\
Hearing loss & $3(15.0)$ & $2(18.2)$ & 1.000 \\
Dizziness & $2(10.0)$ & $1(9.1)$ & 1.000 \\
Comorbidity & & & \\
HBP & $3(15.0)$ & $1(9.1)$ & 1.000 \\
DM & $1(5.0)$ & $0(0.0)$ & 1.000 \\
Site & & & 0.931 \\
Left & $7(35.0)$ & $3(27.3)$ & \\
Right & $5(25.0)$ & $3(27.3)$ & \\
Bilt & $7(35.0)$ & $5(45.5)$ & \\
Head & $1(5.0)$ & $0(0.0)$ & \\
Pitch & & & \\
High & $13(65.0)$ & $10(90.9)$ & \\
Mid & $4(20.0)$ & $1(9.1)$ & \\
Low & $3(15.0)$ & 0.324 \\
Tinnitus status & & & \\
Low & $5(25.0)$ & $0(0.0)$ & \\
Moderate & $7(35.0)$ & $5(45.5)$ & \\
Severe & $8(40.0)$ & $6(54.6)$ & \\
\hline
\end{tabular}

HBP: hypertension, DM: diabetes mellitus 
자군 사이에 유의한 차이가 없었다(Table 3 and 4).

\section{치료 반응}

이명재훈련치료 전과 6개월 후 이명 설문지상 $\mathrm{LD}, \mathrm{AW}, \mathrm{AN}$, $\mathrm{EF}$ 및 $\mathrm{THI}$ 를 비교하였다. Senior 상담자에게 이명재훈련치 료를 받은 환자는 모든 항목에서 감소 추세를 보였고, 특히 $\mathrm{AW}, \mathrm{AN}, \mathrm{EF}, \mathrm{THI}$ 에서 유의한 감소를 보이는 것을 확인하 였다(Fig. 1). Junior 상담자에게 이명재훈련치료를 받은 환 자 또한 대부분의 항목에서 감소 추세를 보였고, 특히 AW, $\mathrm{AN}, \mathrm{EF}$ 에서 유의한 감소를 보이는 것을 확인하였다(Fig. 2).

Table 3. Initial characteristics of the tinnitus questionnaires between senior and junior counselor groups

\begin{tabular}{lccc}
\hline & Senior $(n=47)$ & Junior $(n=31)$ & p value \\
\hline LD & $4.60 \pm 2.16$ & $5.13 \pm 2.51$ & 0.321 \\
AW & $62.43 \pm 33.76$ & $68.71 \pm 33.44$ & 0.414 \\
AN & $5.45 \pm 2.37$ & $5.81 \pm 2.75$ & 0.540 \\
EF & $5.51 \pm 2.51$ & $5.58 \pm 2.79$ & 0.909 \\
THI & $38.62 \pm 24.11$ & $38.00 \pm 23.55$ & 0.911 \\
\hline
\end{tabular}

LD: loudness, AW: awareness, AN: annoyance, EF: effect on life, THI: Tinnitus Handicap Inventory

Table 4. Initial characteristics of the tinnitus questionnaires between two junior counselors

\begin{tabular}{lccc}
\hline & Junior $B(n=20)$ & Junior $C(n=11)$ & $p$ value \\
\hline LD & $4.50 \pm 2.06$ & $6.27 \pm 2.94$ & 0.059 \\
AW & $66.00 \pm 35.00$ & $73.64 \pm 31.39$ & 0.552 \\
AN & $5.35 \pm 2.80$ & $6.64 \pm 2.58$ & 0.218 \\
EF & $5.00 \pm 2.73$ & $6.64 \pm 2.69$ & 0.120 \\
THI & $33.00 \pm 22.62$ & $47.09 \pm 23.47$ & 0.112 \\
\hline
\end{tabular}

LD: loudness, AW: awareness, AN: annoyance, EF: effect on life, THI: Tinnitus Handicap Inventory

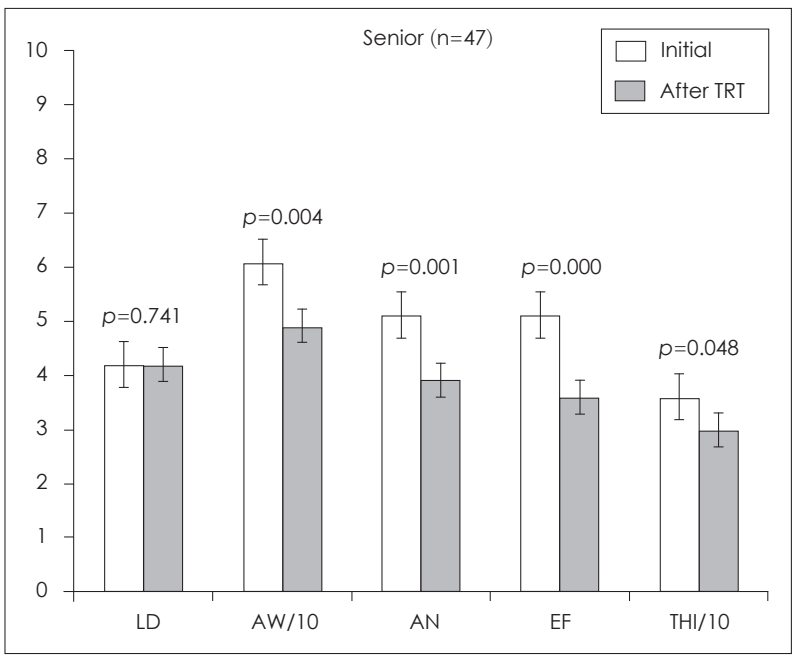

Fig. 1. Treatment response of senior counselor. Tinnitus awareness (AW), annoyance (AN), loudness (LD), effect on life (EF) and the scores of Tinnitus Handicap Inventory (THI) at initial \& 6 months after tinnitus retraining therapy (TRT).

\section{상담자 $\mathrm{A}, \mathrm{B}, \mathrm{C}$ 환자군의 치료 효과 비교}

이명재훈련치료 전후의 설문지에서 각 항목의 델타값 $(\triangle$ value)을 계산하여 치료 후 감소폭이 클수록 치료 효과가 우 수한 것으로 판정하였다. Senior 환자군과 junior 환자군을 비교 분석하였을 때, 두 군에서 $\mathrm{AW}$ 를 제외한 모든 항목에 대한 델타값( $\triangle$ value)의 유의한 차이는 없는 것으로 나타났다. $\mathrm{AW}$ 는 두 군 간에 유의한 차이를 보였는데, junior 환자군에 서 델타값( $\triangle$ value)이 더 많이 감소하였다(Fig. 3). Junior 환 자군 내에서 상담자 $\mathrm{B}$ 와 상담자 $\mathrm{C}$ 의 환자군을 비교해 보았 을 때, 역시 대부분의 항목에서 두 군 간에 유의한 차이가 없 었다. THI는 두 군에서 유의한 차이를 보였으며, 상담자 C에 서 더 큰 폭으로 감소한 것으로 나타났다(Fig. 4).

다양한 통계적 방법으로 접근하여 자료 해석의 신뢰도를 높이기 위해 각 환자군별로 $20 \%$ 이상 이명 설문지 항목들의

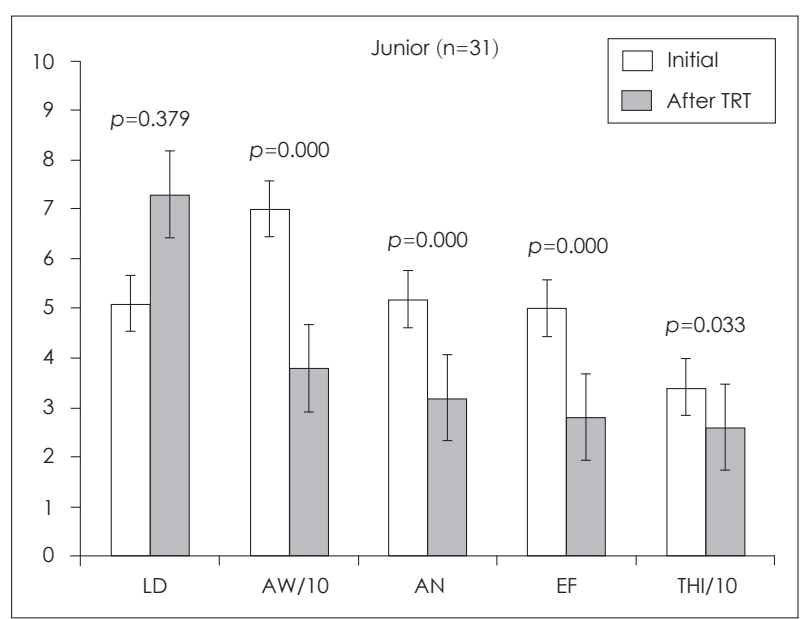

Fig. 2. Treatment response of junior counselors. Tinnitus awareness (AW), annoyance (AN), loudness (LD), effect on life (EF) and the scores of Tinnitus Handicap Inventory (THI) at initial \& 6 months after tinnitus retraining therapy (TRT).

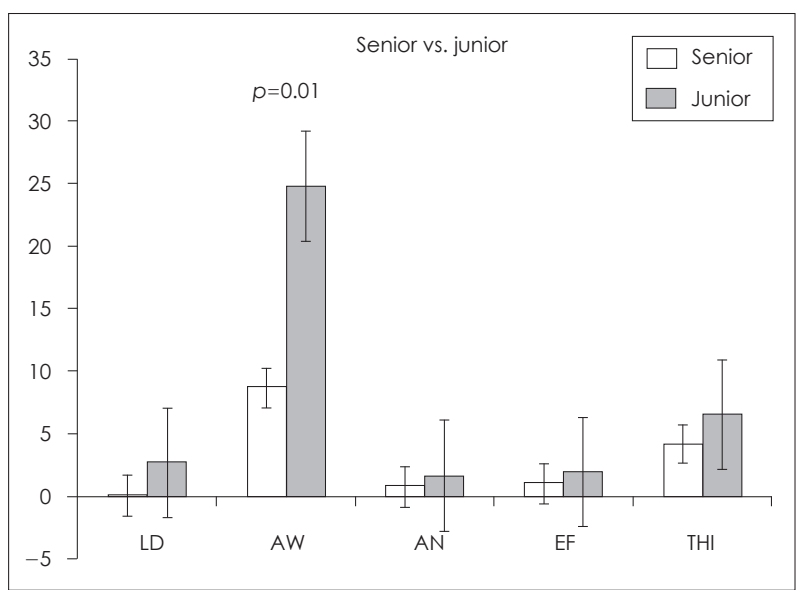

Fig. 3. Comparison of the degree of improvement after TRT between the senior and the junior group C. AW: awareness, AN: annoyance, LD: loudness, EF: effect on life, THI: Tinnitus Handicap Inventory, TRT: tinnitus retraining therapy. 


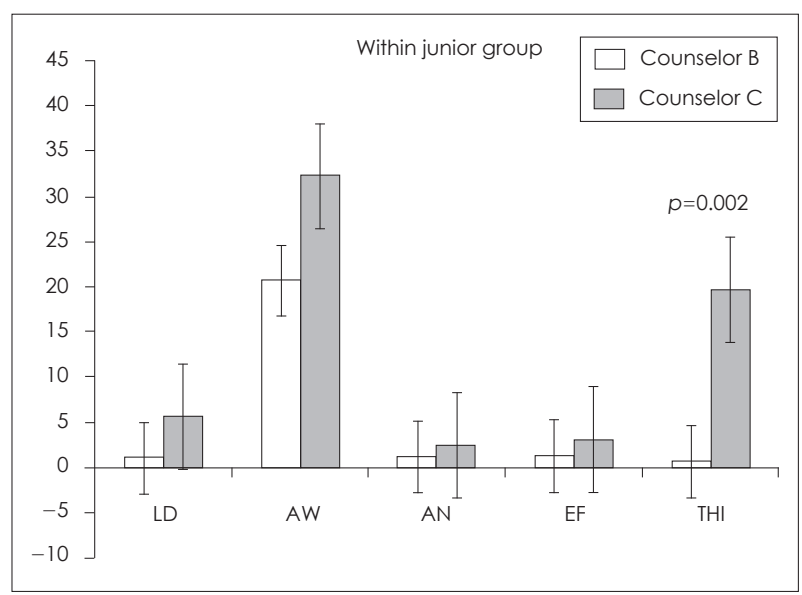

Fig. 4. Comparison of the degree of improvement after TRT between the counselor B and C. AW: awareness, AN: annoyance, LD: loudness, EF: effect on life, THI: Tinnitus Handicap Inventory, TRT: tinnitus retraining therapy.

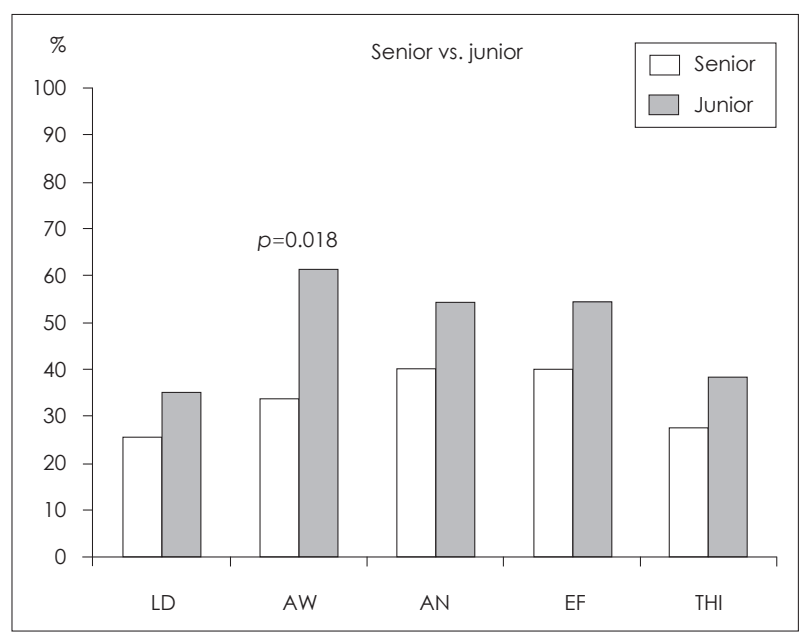

Fig. 5. Comparison of the percentage of the patients who showed reduction of each parameters for over $20 \%$ after TRT between senior and junior groups. AW: awareness, AN: annoyance, LD: loudness, EF: effect on life, THI: Tinnitus Handicap Inventory, TRT: tinnitus retraining therapy.

수치가 감소한 환자의 비율을 계산해 보았다. 치료 후 특정 항목의 수치가 $20 \%$ 이상 감소한다면 치료 효과가 있는 것으 로 가정하였다. Senior 환자군과 junior 환자군을 비교해 보 았을 때 모든 항목에서 두 군 간에 유의한 차이가 없었다 (Fig. 5). Junior 환자군 내에서 상담자 $\mathrm{B}$ 와 상담자 $\mathrm{C}$ 의 환자 군을 비교해 보았을 때, 이 또한 모든 항목에서 유의한 차이 가 없는 것으로 나타났다(Fig. 6).

이상의 결과를 종합해 보면, 이명 환자가 이명재훈련치료 를 받은 후 상담자 $\mathrm{A}, \mathrm{B}$, 그리고 $\mathrm{C}$ 모두에서 대부분의 이명 증 상이 호전되는 것을 알 수 있었고, senior 상담자와 junior 상 담자 사이의 치료 효과 차이, 그리고 경험이 비슷한 서로 다른 상담자 사이의 치료 효과 차이는 없는 것으로 나타났다.

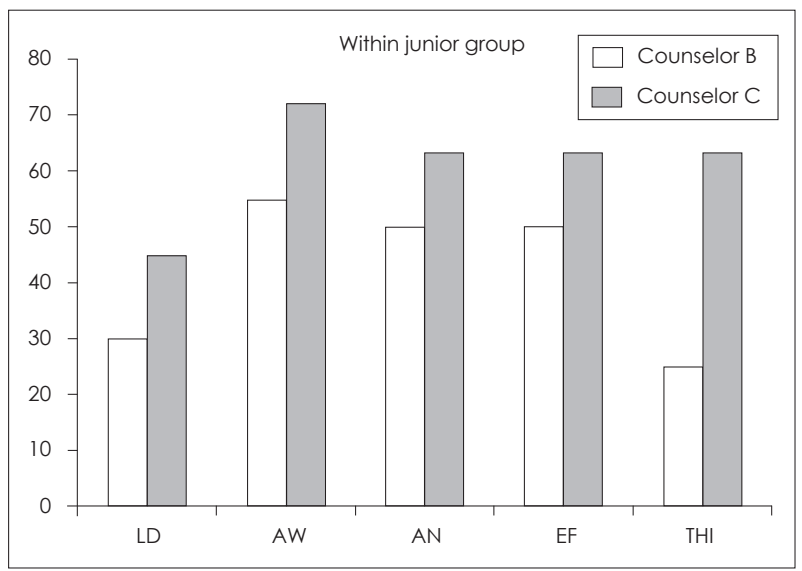

Fig. 6. Comparison of the percentage of the patients who showed reduction of each parameters for over $20 \%$ after TRT between junior counselor B and C. AW: awareness, AN: annoyance, LD: loudness, EF: effect on life, THI: Tinnitus Handicap Inventory, TRT: tinnitus retraining therapy.

\section{고 찰}

본 연구는 귀 질환과 청각, 이명에 대한 지식이 풍부한 이비 인후과 전문의가 이명재훈련치료의 특성을 잘 이해하고 동 일한 프로토콜을 적용할 경우 비슷한 치료 효과를 보일 것 을 가정하고 이를 검증하기 위해 시행되었다. 특히 이명 치료 의 가장 중요한 부분을 차지하는 이명재훈련치료의 지시적 상담에 대해 상담자 요소가 미치는 영향을 분석하는 국내외 의 최초 연구로서 그 결과를 보고함에 중요한 의미를 가진다 고 판단하였다. 연구 결과 동일한 방법을 적용한 이명재훈련 치료의 지시적 상담 효과는 예상대로 이비인후과 전문의 상 담자들 간에 치료 결과가 차이를 보이지 않음을 알 수 있었 다. 이는 이명재훈련치료를 시행함에 있어서 같은 프로토콜 을 따르면서 필수적인 내용을 포함할 경우, 상담자의 경험이 나 숙련도 등의 상담자 개인의 요소가 치료 효과에 큰 영향 을 미치지 않는다는 것을 시사하는 결과라고 볼 수 있다.

이명재훈련치료 전후로 이명 설문지 항목들을 비교 분석하 였을 때(Figs. 1 and 2), 이명의 크기(LD)는 senior군에서 거 의 변동이 없고 junior군에서는 오히려 증가하는 소견을 보 였다. 이것은 통계적으로 유의하지 않을 뿐 아니라 junior군 의 환자수가 상대적으로 적다는 것을 감안하면 의미 있는 소견이라고 보기 어렵다. 이명 설문지의 다른 항목들이 모두 유의하게 감소한 것으로 보아 이명재훈련치료 6 개월 이후 증 상이 호전되었다고 보는 것은 타당하다. 앞으로 더 많은 이명 환자를 대상으로 오랜 기간 누적된 결과에 대한 연구가 필요 하며, 다양하고 많은 상담자를 포함하는 다기관 연구도 과제 로 남아있다.

본 연구는 후향적 연구 결과를 분석한 것으로 상담자 $\mathrm{A}$ 를 
찾았던 환자 중 일부가 상담자 $\mathrm{B}, \mathrm{C}$ 에게 지시적 상담을 받았 고 그 치료 결과를 추적관찰 및 분석하였다. 경험이 많은 상 담자 $\mathrm{A}$ 가 비교적 경험이 적은 상담자 $\mathrm{B}, \mathrm{C}$ 에게 지시적 상담 을 의뢰한 환자들의 성향은 좀 더 긍정적이고 수용적이었을 가능성이 높다고 추정되며, 이로 인해 본 연구의 결과에서 통계적 유의성은 없지만 junior군에서 이명 설문지상 수치의 호전 효과가 더 컸을 가능성이 추론된다. 즉 이명 $\mathrm{AW}$ 점수의 경우 senior군보다 junior군에서 유의한 감소를 보인 결과는 이 같은 본 연구의 후향적 설계의 제한점이 될 수 있겠다. 그 러나 전향적 무작위 배정이 이루어지지 않은 본 연구 결과에 서 대부분의 변수에서 상담자에 따른 치료 효과의 차이를 통계학적으로 관찰할 수 없었기에 향후 무작위 배정 전향적 연구를 시행하여 이를 보다 과학적으로 확인하는 연구가 추 가적으로 필요할 것으로 생각된다.

한편 상담자 요소와는 별개로 모든 환자에서 대부분의 이 명 증상들이 이명재훈련치료 후 호전되었음을 이명 설문지 를 통해 확인하였으며, 이는 다수의 선행 연구들과 일치하는 결과이다. ${ }^{10-14)}$ 하지만 추적관찰이 가능했던 환자군이 추적관 찰에 실패한 환자군보다 이명 설문지상의 치료 효과가 더 우 수하다는 $\operatorname{Han}$ 등 $^{15}$ 의 연구 결과에 비추어 보면, 본 연구에서 는 6개월 후 추적관찰이 가능했던 환자들만을 포함한 점이 바이어스로 작용했을 가능성을 완전히 배제할 수는 없다. 추 후 전화 조사법 등을 통해 추적관찰에 실패한 환자까지 대상 으로 한 연구가 필요할 것으로 생각된다.

고령화 사회가 되면서 난청과 이명의 빈도가 급증하고 있으 며, 의료가 발전하고 우리나라 국민의 사회적, 경제적 수준이 높아지면서 삶의 질과 밀접하게 관련된 증상인 이명의 치료 수요도 더욱 커지고 있다. 이에 본 연구를 통해 이명재훈련치 료에 대한 교육을 받고 지식이 충분한 이비인후과 전문의라 면 누구나 좋은 치료 효과를 기대하며 이명재훈련치료를 적
극적으로 시행할 수 있는 근거를 제시하고자 한다.

\section{REFERENCES}

1) Jastreboff PJ. Phantom auditory perception (tinnitus): mechanisms of generation and perception. Neurosci Res 1990;8(4):221-54.

2) Jastreboff PJ, Gray WC, Gold SL. Neurophysiological approach to tinnitus patients. Am J Otol 1996;17(2):236-40.

3) Jastreboff PJ, Jastreboff MM. Tinnitus retraining therapy (TRT) as a method for treatment of tinnitus and hyperacusis patients. J Am Acad Audiol 2000;11(3):162-77.

4) Jastreboff PJ. 25 years of tinnitus retraining therapy. HNO 2015;63 (4):307-11.

5) Chung SW, Suh MW. Short term effect of mixed tinnitus retraining therapy. Korean J Otorhinolaryngol-Head Neck Surg 2011;54(10): 693-8.

6) Lee HK, Kim CW, Chung MH, Kim HN. The effectiveness of the directive counseling in tinnitus retraining therapy. Korean J OtolaryngolHead Neck Surg 2004;47(3):217-21.

7) Park SN, Bae SC, Kim DK, Park YS, Yeo SW, Park SY. Small-group counseling in a modified tinnitus retraining therapy for chronic tinnitus. Clin Exp Otorhinolaryngol 2013;6(4):214-8.

8) Kim BJ, Chung SW, Jung JY, Suh MW. Effect of different sounds on the treatment outcome of tinnitus retraining therapy. Clin Exp Otorhinolaryngol 2014;7(2):87-93.

9) Park SN, Yeo SW, Chung SH, Rhee SJ, Park YS, Suh BD. Clinical implication and therapeutic efficacy of tinnitus retraining therapy. Korean J Otolaryngol-Head Neck Surg 2002;45(3):231-7.

10) Jastreboff PJ, Jastreboff MM. Tinnitus retraining therapy: a different view on tinnitus. ORL J Otorhinolaryngol Relat Spec 2006;68(1):239; discussion 29-30.

11) Jastreboff PJ. Tinnitus retraining therapy. Prog Brain Res 2007;166: 415-23.

12) Bauer CA, Brozoski TJ. Assessing tinnitus and prospective tinnitus therapeutics using a psychophysical animal model. J Assoc Res Otolaryngol 2001;2(1):54-64.

13) Jastreboff PJ, Jastreboff MM. Tinnitus retraining therapy for patients with tinnitus and decreased sound tolerance. Otolaryngol Clin North Am 2003;36(2):321-36.

14) Johnson RM, Brummett R, Schleuning A. Use of alprazolam for relief of tinnitus. A double-blind study. Arch Otolaryngol Head Neck Surg 1993;119(8):842-5.

15) Han JJ, Lee JH, Oh SH, Chang SO, Suh MW. Assessing the effects of tinnitus retraining therapy in patients lost to follow-up: a telephone survey. Otol Neurotol 2015;36(4):581-7. 